\title{
Autonomias errantes: Processos de autonomização em saúde mental
}

Marciana Zambillo. Universidade Federal do Rio Grande do Sul.

Analice de Lima Palombini. Universidade Federal do Rio Grande do Sul.

\section{Resumo}

No Brasil, o campo da saúde, em especial a saúde mental, adota o conceito de 'autonomia' e o explicita em grande parte de suas políticas públicas. Não há, no entanto, descrição ou problematização do termo, o que pressupõe um entendimento a priori, naturalizado. $\mathrm{O}$ objetivo deste artigo é abordar a ideia de autonomia pelos vieses conceitual e performático. Como conceito, o termo é problematizado e atualizado à luz de teorias contemporâneas, as quais são contrapostas brevemente às conceituações hegemônicas na história da filosofia. Como performance, ele se relaciona à experiência de uma viagem à Montreal-CA, que durou quinze dias e ocorreu em novembro de 2013. Dez pessoas participaram dessa viagem, entre eles usuários de saúde mental, familiares e discentes das universidades envolvidas na pesquisa. Utiliza-se a metodologia cartográfica para produção e análise dos dados. Consideram-se todos os participantes como pesquisadores, na tentativa de dissolver os lugares de sujeitos de pesquisa e pesquisador, valorizando a experiência.

Palavras-chave: autonomia; saúde mental; cartografia.

\begin{abstract}
Errant autonomies: Processes of autonomisation in mental health. In Brazil, the health field, especially mental health, adopts the concept of autonomy and exposes it in most of its public policies. There isn't, however, a description or a problematization of the term, which presupposes an a priori understanding, naturalized. The aim of this article is to approach the idea of autonomy from conceptual and performative perspectives. As a concept, the term is problematized and updated in the light of contemporary theories, which are briefly set against the hegemonic concepts in the history of philosophy. As a performance, it is related to the experience of a trip to Montreal-CA, which lasted fifteen days and happened in November 2013. Ten persons took part in this trip, including mental health users, family members and students from universities involved in research. In order to produce and analyze the data, cartographic methodology is used. All the participants are considered researchers, in an attempt to dissolve the places of research's subject and researchers, valuing the experience.
\end{abstract}

Keywords: autonomy; mental health; cartography.

\section{Resumen}

Autonomías errante: Procesos de autonomización en salud mental. En Brasil, el campo de la salud, especialmente la salud mental, adopta el concepto de "autonomía" y explícita en gran parte de sus políticas públicas, sin embargo, describir o discutir el plazo, asumir un conocimiento a priori, nación. El propósito de este artículo es hacer frente a la autonomía por el sesgo conceptual y performativo. Como concepto, se analiza y actualiza el plazo a la luz de las teorías contemporáneas, opuesto brevemente a las concepciones hegemónicas en la historia de la filosofía. Como el rendimiento, presenta la experiencia de un viaje a MontrealCA durante dos semanas en noviembre de 2013, celebrado por diez personas entre usuarios de salud mental, las familias y los estudiantes de las universidades que participan en la investigación. La metodología utilizada para la producción cartográfica y análisis de datos, teniendo en cuenta todos los participantes como los investigadores y disolviendo el tema de los lugares de la investigación y el investigador, la valoración de la experiencia.

Palabras clave: autonomía; salud mental; cartografía. 
As políticas públicas brasileiras de saúde, em especial a saúde mental, demonstram apreço pelo termo 'autonomia' ao incluí-lo na maior parte de seus textos legislativos. Com que conceituação de autonomia operam? Se o uso irrestrito do termo pode apontar a pluralidade de sentidos que são possíveis de se atribuir ao conceito, também sugere ausência de discussões e uma possível naturalização do mesmo. Interessa, neste artigo, questionar que autonomia é possível em saúde mental. Na tentativa de resposta, operou-se um deslocamento na questão: não se questiona quem é, ou seja, a pergunta não é se "os usuários de saúde mental são autônomos", mas "quando há autonomia em saúde mental". Que devir-autônomo é possível em saúde mental? Trata-se, portanto, de um questionamento sobre as performances das autonomias. Ou, ainda, sob quais condições e critérios são possíveis ações de autonomia no contexto da saúde mental.

Elegeu-se, como território das performances, um não-lugar, um laboratório de imersão ilocalizável, uma viagem de quinze dias à Montreal, no Quebec, Canadá, realizada por dez pesquisadores - entre usuários, familiares e discentes envolvidos na pesquisa e estratégia Gestão Autônoma da Medicação (GAM).

O artigo está dividido em quatro partes: aposta metodológica que permitiu acompanhar o processo; narrativas de um laboratório de imersão; formas de uso do conceito de autonomia na história da filosofia ocidental; reflexões finais que contrastam a experiência de imersão às formas de conceituar autonomia, afirmando-a como processo de autonomização.

\section{Sobre acompanhar um processo}

Trata-se de uma pesquisa cartográfica com pretensão de acessar experiências de autonomização em saúde mental. Busca-se acompanhar processos de produção e atualização de realidades, não para apresentar um estado de coisas, mas dar vistas a um processo. O processo em questão se refere ao acompanhar de dez pessoas (incluindo a pesquisadora) na condição de pesquisadores-usuários de saúde mental, pesquisadores-trabalhadores e pesquisadores-acadêmicos (docentes e discentes) em uma viagem a Montreal, em novembro de 2013, para um encontro de formação internacional de pesquisas imbricadas entre comunidades e universidades.

Segundo Alvarez e Passos (2009), cartografar é sempre compor com um território existencial, engajando-se nele. Deve-se tomar distância da tentação de defini-lo, de tratá-lo como exterior e prévio, capaz de ser representado por um olhar objetivo e objetivante. Deleuze e Guattari (1997) enfatizam a dimensão processual e qualitativa do território, que o torna existencial. "O território é antes de tudo lugar de passagem", dizem os autores (p.132). Ousamos levar esse enunciado à sua máxima radicalidade, ao tomar uma viagem como território a habitar. Viagem a um país desconhecido, a uma língua insabida, território errante em que o pesquisador titubeia, tropeça e se dissolve.

Dissolver o ponto de vista do observador não significa abdicar da observação, mas, sim, dessa inversão que situa a experiência em instâncias predeterminadas como sujeito e objeto de pesquisa. Atingir a dissolução do pesquisador no campo diz respeito a assumir como primordial a indissociabilidade entre sujeito e objeto, reconhecendo a experiência como base do coengendramento de si e do mundo (Passos \& Eirado, 2009). É dissolver-se no procedimento narrativo da 'desmontagem' das cenas, fazer as conceituações e os usos de autonomia nas práticas de saúde mental gaguejarem, tecer as tramas do agenciamento coletivo de enunciação e as supostas individualidades.

Para Kastrup e Passos (2013), a produção de um plano comum entre sujeito e objeto, se dá pelo acesso à dimensão processual dos fenômenos que se investiga. Isto é, parte-se do pressuposto que conhecer algo é também criar este algo, a isto se chama poiesis: uma dimensão da realidade em que ela se apresenta como processo de criação, em que conhecê-la e produzi-la se dá em um mesmo movimento.

Ainda segundo Kastrup e Passos (2013), o comum se define por sua consistência experiencial e concreta, em que se realiza a partilha de um comum e, consequentemente, cria-se o efeito de pertencimento. $\mathrm{O}$ comum porta o duplo sentido de partilha e pertencimento; é aquilo que partilhamos e em que tomamos parte, pertencemos, nos engajamos. A cartografia traça e acessa o plano comum e coletivo abrindo e ampliando as relações intra e intergrupais. Os autores alertam que não se reduza o coletivo a uma soma de indivíduos ou ao resultado do contrato que fazem entre si. Antes disso, é uma rede de composição ilimitada de seres que produzem realidades. No plano de produção, plano coletivo das forças, não há propriedade particular, nada que seja privado, já que todas as forças estão disponíveis para serem experimentadas.

Acessar esse plano comum é o movimento que sustenta a construção de um mundo comum e, 
simultaneamente, heterogêneo. Para Kastrup e Passos (2013), há um limite instável entre o que comuna e o que difere; "entre o que conecta os diferentes sujeitos e objetos implicados no processo de pesquisa e o que, nessa conexão, tensiona; entre o que regula o conhecimento e o que o mergulha na experiência" (Kastrup \& Passos, 2013, p. 267).

Não há, portanto, coleta de dados em cartografia, mas produção de dados, pois o que está em questão, diferentemente do método da ciência moderna, não é isolar o objeto de suas articulações históricas nem de suas conexões com o mundo e então coletar informações. Ao contrário, "o objetivo da cartografia é justamente desenhar a rede de forças à qual o objeto ou fenômeno em questão se encontra conectado, dando conta de suas modulações e de seu movimento permanente" (L. P. Barros \& Kastrup, 2009, p. 57). No entanto, ressaltam as autoras, a ausência de um controle purificador da ciência experimental, não significa uma entrega ao espontaneísmo. O que há, é um deslocamento no modo como o pesquisador opera a atenção, utilizando-se de uma concentração sem focalização.

A viagem a Montreal serviu de laboratório de imersão. A sugestão era de que fizéssemos uso compartilhado, entre todos os viajantes, de equipamentos para vídeos e fotografias, com o intuito de registrar e posteriormente narrar coletivamente a experiência. Diários de campo e hypomnemata (cf. Foucault, 2006), fotografias e vídeos decorrentes desse processo foram, assim, utilizados como ferramentas metodológicas, como produção coletiva que, ao mesmo tempo em que enceta movimentos de autonomização, dá testemunho desses movimentos. Portanto, tal proposta não se assemelha à captura do real, mas à produção de realidades, numa construção de linguagem em pesquisa que fosse alternativa à linguagem puramente escrita, contemplando-se aí o pesquisarCom. Entendemos que pesquisar com o outro, como explicam Moraes e Kastrup (2010, p. 07), tem mais a dimensão de verbo do que de substantivo, pois implica uma concepção de pesquisa que é engajada e situada no modo de fazer no cotidiano da pesquisa e do campo. Indica que é preciso acompanhar os processos em ação, fazendo-se na prática cotidiana das pessoas que vivenciam a problemática investigada. Assim, pesquisar com aquele para quem a pesquisa se destinaria não a torna mais ou menos verdadeira, mas mais próxima aos interesses dos que são atingidos diretamente pelos conhecimentos produzidos (usuários, familiares e trabalhadores). Como explicam Passos e
Barros (2009), a exigência de uma suposta neutralidade nas relações de pesquisa entre sujeito/objeto não se sustenta, neste método, pois se considera que todos os sujeitos envolvidos estão implicados na constituição de conhecimento, na criação de realidades e nas suas consequências políticas. Impossível, portanto, traçar metas a serem atingidas a priori; tratou-se, antes, de apostar na oportunidade de esticar o conceito de autonomia, criar redes coletivas e escapar de tutelas.

\section{Laboratório In vita: A viagem}

A construção do território de viagem é anterior à decolagem. Surge de uma pesquisa multicêntrica, desenvolvida em diferentes cidades brasileiras entre os anos de 2010 e 2014, envolvendo parceria entre Brasil e Canadá na pesquisa GAM. A pesquisa objetivava tornar visível a pluralidade de relações estabelecidas com o uso de psicofármacos, ressaltando a necessidade de compartilhamento das decisões sobre seu uso entre os profissionais e usuários de serviços de saúde mental. Fez-se a tradução, testagem e adaptação para a realidade brasileira do Guia da Gestão Autônoma da Medicação criado por associações de usuários e serviços alternativos de saúde mental quebequense - intitulado para nós de Guia Brasileiro da Gestão Autônoma da Medicação (Guia GAM-BR), além de elaborar o Guia de Apoio a Moderadores de Grupos GAM-BR, ambos disponibilizados, para uso público, em versão on-line http://www.fcm.unicamp.br/fcm/laboratorio-saude-coletiva-e-saude-mental-interfaces. Os materiais estão sustentados nas concepções de que o tratamento em saúde mental é mais abrangente que o uso de medicamentos e que os usuários são pessoas, não são doenças.

Ao longo da pesquisa, a relação estabelecida - através de videoconferência ou por Skype - entre pesquisadores-usuários de saúde mental brasileiros e quebequenses suscitou o desejo de um encontro presencial. Tal desejo deu vazão à criação de um Encontro de Formação durante a segunda quinzena de novembro de 2013. A proposta do Encontro incluía visitações a serviços de saúde alternativos aos oferecidos pelo Estado (ainda que financiados por meio de políticas públicas, mantinham gestão externa e independente); apresentação, pelos pesquisadores-usuários de ambos os países, dos movimentos sociais em que se encontravam engajados; planejamento das ações para o último ano do projeto de parceria, com ênfase para as futuras publicações e divulgação do trabalho desenvolvido. 
A data estipulada para o Encontro de Formação não era favorável aos pesquisadores-docentes e, portanto, discutiu-se, em uma reunião multicêntrica brasileira, a possibilidade de adiamento da viagem. Os usuários, no entanto, optaram que a data fosse mantida, mesmo que somente eles pudessem viajar. Também estavam dispostos a cortar custos, se assim pudessem aumentar o número de usuários-viajantes. Afirmavam assim, em ato, sua vontade de autonomização, muito à frente do que pesquisadores-acadêmicos poderiam, naquele momento, imputar-lhes como possibilidade.

O custeamento para as passagens, alimentação, estadia e deslocamentos foi fornecido pela agência canadense de fomento da pesquisa e cobria os gastos de até cinco pesquisadores-usuários. Os pesquisadores-acadêmicos, por sua vez, poderiam tentar financiamento junto às suas instituições de ensino superior. Assim, por vontade dos usuários, a verba prevista para cinco passageiros foi dividida a fim de contemplar oito pessoas, sendo sete usuários e uma familiar. Uma estudante de Doutorado do estado de São Paulo e uma de nós, autoras deste artigo, do estado do Rio Grande do Sul, conseguimos financiamento em nossas universidades. Outras tentativas foram realizadas, como a arrecadação de contribuição espontânea para mais pesquisadores-usuários pela internet, no entanto, sem sucesso. Aqui havia um processo de autonomização sendo experimentado.

Em novembro de 2013, embarcamos para Montreal-QC, no Canadá, para ficarmos durante 15 dias. Éramos uma usuária de saúde mental do Rio de Janeiro/ RJ, uma de Novo Hamburgo/RS, um de São Leopoldo/ $\mathrm{RS}$, quatro usuários e uma familiar de Campinas/SP, uma estudante de doutorado de Campinas/SP e uma estudante do mestrado de Porto Alegre/RS - todos em interlocução privilegiada, acompanhados no trajeto de ida por uma estudante de doutorado de Montreal/CA, brasileira e participante nos anos iniciais da pesquisa no Brasil.

A autora deste artigo, que embarcou nessa viagem, solicitou aos usuários que pudesse ficar hospedada junto a eles, e assim ficaram 15 dias juntos, com raros momentos de distanciamento. Criaram-se, dessa forma, peculiaridades do encontro, belas e espinhosas, que tornaram desafiador acompanhar um processo, fazer parte dele, arcar com as inúmeras possibilidades de tropeços.

A viagem marca uma experiência de imersão. Um laboratório. Era a chance de nos lançarmos num terreno desconhecido com obstáculos diversos. Estávamos longe de nossos lares, afastados das pessoas com quem convivíamos diariamente, com as quais, de alguma maneira, sabíamos como lidar. Deixávamos o Brasil nos dias que antecediam o verão, para alcançarmos o Quebec às vésperas de um inverno rigoroso - ao menos quando comparado ao frio que até então conhecíamos. Não falávamos nem a primeira língua do país de destino, nem a segunda. Nossos recursos financeiros eram limitados. Precisávamos manter a boa convivência entre nós. Distantes demais das pessoas queridas a quem deixávamos, próximos demais de nós mesmos. Esta era a configuração de um laboratório de imersão, o qual precisaríamos suportar por 16 dias e 15 noites. Com esta configuração, tínhamos a oportunidade de esticar o conceito de autonomia, de fazer acontecer - como o teorizávamos - a possibilidade de criar redes e encontrar pontos de apoio na coletividade para nos tornarmos independentes. Ao mesmo tempo, era a possibilidade de administrarmos uma autonomia sob o risco constante de sermos capturados pela tutela daqueles que nos ajudariam, daqueles que seriam nosso ponto de apoio. Tínhamos o desafio de superar os obstáculos por meio de ajuda e suporte dos demais, sem nos deixarmos tutelar. Fazer da ajuda e dos pontos de apoio fontes de autonomização, que caminhassem mais próximos de nosso desejo e vontade - negociados no desejo do mundo (daquilo que é possível ser no mundo) e no desejo do coletivo (daquilo que é negociável).

Viajávamos como pesquisadores e em virtude da pesquisa que sucedera no Brasil. Embarcamos com um cronograma de trabalho pré-estabelecido, conforme a proposta inicial, com margens para modificações e imprevistos.

A sistematização da produção de dados para aqueles dias de imersão seria através da escrita, da fotografia e de vídeos. Parte dessa produção, com destinação ao público, foi disponibilizada no blog (http:// diariodebordodeunsloucos.blogspot.com.br). Na vivência em laboratório, no processo de pesquisa in vita (e não in vitro), arcamos com a imprecisão, não só do lugar do pesquisador, mas das fronteiras entre vida e laboratório, intimidade e público. Tentamos trazer à tona este lugar híbrido do pesquisar: por um lado, é pautado pela necessidade de registro (em narrativa, em foto e em vídeo); por outro, ao fazer seu 'próprio percurso', nem sempre pode se fazer registrar. Nessa acepção, o pesquisar carrega a marca do 'percurso da vida', da não-autoria, do acontecimento. Acontecimento, aqui, faz referência à ideia de Deleuze (Zourabichvili, 2004), 
entendido na forma como o propõe Deleuze: como ruptura que corta o tempo e o força a recomeçar, numa apreensão sintética do irreversível e do iminente, dando-se numa ordem de aîon (tempo intempestivo) e não de um tempo chronos (tempo ordenado), controlado e controlador - o que escapa a qualquer formalização, o que desequilibra, subverte (Deleuze, 1974; Zourabichvili, 2004).

A imersão mantinha sob sua atmosfera uma dimensão de formação, de pesquisa, de discussão orientada. Referimo-nos, aqui, ao cronograma do evento, às rodas de discussão e aos interesses que nos moviam a cada encontro. Toda a temática girava em torno da saúde mental, dos direitos dos usuários, das estratégias de autonomização, da criação de serviços de saúde com qualidade. O cronograma se fazia dentro da vida que seguia e que estava deslocada de seu cotidiano. Durante o dia, orgulhávamo-nos ao ouvir as experiências dos pesquisadores-usuários que negociavam em seus serviços e com seus médicos a modificação, redução ou eliminação dos psicofármacos de seu cotidiano, em nome de um modo de vida que mais lhes conviesse. À noite, nos intervalos, nos finais de semana, circulava pela casa o zum-zum acerca daqueles que não estariam muito bem; a névoa de medo de ameaças de crises psicóticas, depressivas, estressantes. Fervilhava o mal estar daqueles que se isolavam e não queriam contato, daqueles que desconfiavam das pessoas ao seu redor, do choro ao telefone durante as conversas com familiares e do temor de adoecer longe destes. Nenhum de nós estava imune a estes sofrimentos, alguns mais suscetíveis que outros - e isto em nada faz referência à existência de um diagnóstico psiquiátrico que nos fora atribuído ou ao uso de psicofármacos. Segue abaixo duas narrativas referentes às crises experimentadas no laboratório, registradas em diário de campo e posteriormente publicadas na dissertação (Zambillo, 2015):

\footnotetext{
CENA I

[...] Alguns perguntavam por que não pegávamos um táxi, outros insistiam para que saíssemos logo. Precisávamos tomar alguma decisão. Um dos pesquisadores-usuários disse que eu deveria decidir o que faríamos e dar as coordenadas. Senti-me agredida. Uma resposta áspera acompanhada de uma vontade de choro dizia que eu não podia resolver aquilo. Outro pesquisador-usuário pediu para não me pressionarem, que eu ficaria ansiosa e não aguentaria. Eu estava diante de uma crise, e de alguma forma aquele pesquisador-usuário sabia como manejá-la. [...] (p. 130).
}

\section{CENA II}

[...] Um dos pesquisadores-usuários disse estar se sentindo muito desconfiado. Temia ter uma crise psicótica. Conversou com a pessoa do grupo em que mais confiava e fizeram um acordo: se ele se sentisse mal naquela noite, procuraria por mim. Fui avisada e pega de surpresa. Por que ele quereria conversar comigo? Desconfiei de que tal decisão passava longe da minha formação. Lembrei que, durante a tarde, enquanto almoçávamos num shopping, ele me disse que via em mim muito de si. Não era o suficiente para eu saber as razões de ele ter me eleito; de qualquer forma, estava de sobreaviso.

De manhã fui acordada com o cheiro de café (havia sempre um pesquisador-usuário bem-disposto que acordava cedo para passá-lo). Logo chegou o pesquisador-usuário que estava desconfiado. Ele me disse que Sofia me mandara um beijo. Não entendi. Ele explicou que, durante a noite, veio conversar comigo (conforme o combinado), mas eu estava dormindo e, com dó, desistiu de me acordar. Optou então por conversar com sua alucinação, a Sofia. Ao retornar para a cama, percebeu que seu companheiro de quarto estava bastante angustiado, com medo. Juntamente com Sofia, eles fizeram alguns exercícios de ioga e de respiração. (p. 131).

Nosso laboratório, parafraseando Galeano (2007, p. 06), aproxima-se da experiência de Alice, que, depois de conhecer o País das Maravilhas, entra em um espeIho para visitar o mundo do avesso. Um mundo que estava à vista de todos. Um mundo com o umbigo nas costas e os pés na cabeça; um laboratório que desafia muito mais do que protege, que contamina mais do que imuniza, que se abre mais do que restringe. Nosso laboratório não era um ambiente fechado e protegido como o das ciências positivistas; longe disso, era um local novo, desconhecido, com línguas que não falávamos.

A viagem serviu como experiência radical do conceito de autonomia, como ato do que até então se apresentava em exercício. Esse caminho foi possível pelos sapatos calçados ao caminhar, isto é, a metodologia que compõe a GAM como pesquisa e aposta na produção científica realizada com os usuários, que vivem em sua carne e em seu cotidiano a experiência do sofrimento mental e do uso de psicofármacos.

Em 2014, já em solo brasileiro, conversamos sobre produzir uma narrativa compartilhada da viagem e que este material fosse pensado como parte de uma dissertação. Quando começamos a nos encontrar para 
produzir a narrativa coletiva, os pesquisadores-usuários de Campinas-SP estavam empenhados na produção de um curta-metragem para enviá-lo ao Festival Seda, organizado pelo Fora do Eixo ${ }^{1}$. O trabalho para produzir o curta-metragem e a narrativa tinham funções e exigências bastante parecidas. Tratava-se de contar a viagem que havíamos feito, resgatar aquela experiência no estrangeiro e transformá-la em instrumento de luta pela saúde mental em nosso país. Assim, estas duas produções caminharam lado a lado. A produção audiovisual intitulada A viagem continua... (Santarosa \& Dimov, 2014) está disponível online.

\section{Discussão contemporânea do conceito de autonomia}

Grande parte das discussões acerca da autonomia se pauta em contrastá-la com a heteronomia, quer dizer, contrapõe-se a esfera individual de impor leis a si mesmo (autodeterminação) à esfera social (determinações exteriores, interpessoais, culturais, sociais). Para escapar desta dicotomia, Eirado e Passos (2004) recorrem ao conceito de autonomia de sistema, de Varela, considerando o efeito de retroação da autonomia sobre si mesma. Isto é, ela engoliria a heteronomia tornando-a seu princípio, constituindo-se como a sua possibilidade. Assim, "é preciso que se pense a autonomia não apenas como o ato de determinar-se a si mesmo, no sentido fraco, mas como o ato de criar-se a si mesmo, no sentido forte" (Eirado \& Passos, 2004, p. 79). Os autores alertam, no entanto, que, para fazer o deslocamento de autodeterminação para autocriação, é preciso abandonar a dicotomia criador-criatura, pois estes "se entrelaçam formando um circuito, no qual se diferenciam sem, contudo, poderem se separar" (Eirado \& Passos, 2004, p. 79). A dificuldade em pensar a autonomia reside, segundo eles, na "tentação sempre renovada de separar e opor radicalmente planos que, embora distintos, não podem ser concebidos um sem o outro e são inseparáveis" (Eirado \& Passos, 2004, p. 79). Dito de outro modo, trata-se de considerar um deslocamento: ao invés da autonomia fixada na individualidade, propõe-se o seu entendimento em movimento.

Se dermos um breve passeio pela história da filosofia ocidental, podemos extrair algumas notícias dos usos que se fizeram do termo autonomia:

a) A autonomia na Grécia estava referenciada à polis, não aos cidadãos. Seu conceito dizia mais respeito a uma autarcia (autogoverno) do que à autonomia (impor leis a si mesmo). Os indivíduos deveriam submeter seus instintos à razão, em nome da organização e da independência da cidade (Aristóteles, V a.C/ 2011).

b) Em Kant (1785/2011) a autonomia é pensada para o sujeito - um sujeito racional que é capaz de submeter sua vontade à racionalidade $\mathrm{e}$ assim agir moralmente. A teoria moral em Kant tem validade universal e é anterior a qualquer experiência, isto é, tem-se um imperativo categórico que deve ser seguido independente da experiência, pois ele é válido de antemão, de forma que as experiências é que devem se pautar nele. As proposições kantianas ganham força e são influências ainda na contemporaneidade - nos direitos humanos, por exemplo.

c) A crítica de Nietzsche (1882/1999) é contra a teoria moral kantiana, pois vê nela um erro grave ao ter pretensão de universalidade e se propor em anterioridade à experiência. Nietzsche não faz uma defesa da autonomia, ao contrário, critica fortemente o homem autônomo (de Kant), pois vê nele um ser que é capaz de empenhar a sua palavra no futuro (prometer, impor leis a si), sendo que, para isso, nega a potência de criação da vida, deixa de criar para obedecer.

d) A partir da psicanálise, cria-se um problema importante para a autonomia, que até então vinha sendo definida pela capacidade racional dos agentes: ao formular a hipótese do inconsciente, a psicanálise propõe que há no humano uma esfera desconhecida por ele mesmo e ingovernável (Foucault, 2000; Poli, 2006).

e) Na ética aplicada Principialista, a autonomia é um dos quatro princípios prima facie utilizados pela ética biomédica, os outros três são beneficência (promover algum bem ao paciente), não-maleficência (evitar danos) e justiça (distributiva). O princípio de autonomia, para Beauchamp (2007), está associado a ideias, como privacidade, voluntariedade - consentimento informado, liberdade de escolha, responsabilização pelas escolhas feita, não coação, capacidade deliberativa, existência de opções. A ação autônoma precisa atender a condições indispensáveis de (1) intencionalidade - os atos são intencionais ou não-intencionais, não 
há graduação, não há atitude mais ou menos intencionada, ou são intencionadas ou não são; (2) entendimento - pode estar satisfeito em maior ou menor grau; e (3) sem influências controladoras que determinem sua ação (com liberdade) - pode estar satisfeito em maior ou menor grau (Beauchamp \& Childress, 2002).

f) Maturana e Varela (2004) compreendem que os seres vivos só podem ser considerados autossuficientes quando tomados isoladamente, pois, quando se considera a relação com o meio, percebe-se a dependência de recursos externos para viver. Nessa lógica, autonomia e dependência deixam de ser opostos excludentes para serem complementares, de forma que uma constrói a outra numa dinâmica circular.

A busca por estas notícias tem o propósito de fazer pensar qual autonomia é possível em saúde mental. Há algum modelo de autonomia a que temos nos prendido nos modos de fazer saúde? Qual é ele? Que outros modos são possíveis de pensar e argumentar? Neste percorrido, temos uma autonomia universalista; contra ela, uma aposta na singularidade e autocriação - além da criação do inconsciente, que abala o seu reinado. O que propomos a seguir é outro desvio desta autonomia universal. Não a recusaremos, como o fazem Nietzsche e a psicanálise, mas apostaremos em outra via, em um a posteriori, feito de modo compartilhado e com espaço para experiências de loucura.

$\mathrm{Na}$ teoria da biologia do conhecimento, de Maturana e Varela (2004), tem-se a noção de autonomia no sentido de autocriação e autopoiese, sendo o ser vivo o domínio por excelência da autonomia, já que sua existência se define e se constrói a partir de atos pragmáticos. Gama (2010) reconstitui este raciocínio, alegando que o centro da argumentação em A Árvore do Conhecimento (Maturana \& Varela, 2004) é constituído por duas vertentes: (a) o conhecimento não é meramente o processamento de informações oriundas de um mundo anterior à experiência do sujeito que conhece, em que o sujeito se apropria da experiência para fragmentar e explorar o mundo; (b) os seres vivos são capazes de produzir seus próprios componentes ao interagir com o meio: vivem no conhecimento e conhecem no viver.

Para atualizar nos seres humanos a dinâmica da autonomia, é preciso entender os humanos como parte do mundo, é preciso observar a si mesmo enquanto se observa o mundo. Esse passo é fundamental, pois permite compreender que, entre ser humano e mundo, não há hierarquia nem separação, mas sim cooperatividade. Maturana e Varela (2004) inferem que os seres vivos são autônomos quando considerados isoladamente, imaginando-os em bolhas. Todavia, quando se considera a relação com o meio, há que se admitir que eles dependem de recursos externos para viver. Nessa lógica, autonomia e dependência deixam de ser opostos excludentes para serem complementares, de forma que uma constrói a outra numa dinâmica circular. Aqui se deflagram os seres vivos por sua organização autopoiética, ou seja, por sua capacidade de produzir de modo contínuo a si próprios. Nas palavras dos autores: "sua organização [é] tal que seu único produto são eles mesmos, inexistindo separação entre produtor e produto. O ser e o fazer de uma unidade autopoiética são inseparáveis" (Maturana \& Varela, 2004, p. 89). Segundo Gama (2010), é essa organização que permite mostrar como a autonomia se torna explícita na relação e especificação de si mesmo, presente na organização autopoiética.

Se pensarmos em breves notas sobre a Autonomia nas Reformas Brasileiras (Sanitária e Psiquiátrica), encontraremos referências à Kinoshita (2001). Para ele, com inspiração em Canguilhem, autonomia é a capacidade do indivíduo de gerar normas para a própria vida a partir da ampliação de suas relações sociais. Considera-se como autônomo aquele que estabelece maior número de relações em rede. Uma vez que sujeito e mundo se mantêm em relação de codependência, então a ampliação da autonomia consiste no aumento de inserção em relações desse tipo.

Assim, não se entende a autonomia individual como autossuficiência, mas como capacidade de estabelecer redes e se retroalimentar - é pela insuficiência que se ajuda e se busca apoio nos demais; é pela ajuda recebida que se torna suficiente, nunca autossuficiente, sempre suficiente pelo que se compartilha. Tal concepção torna a noção de autonomia próxima à do conceito de cogestão.

Pelas linhas teóricas que seguimos até aqui, podemos assinalar a implicação do uso conceitual e performático do termo autonomia em ações morais, éticas e políticas. Consideramos pertinente, então, marcar a diferença entre uma ética de fundamento e uma ética de fundação.

Há uma discussão ética baseada em fundamentos e outra em fundação. A discussão baseada em 
fundamentos, como a teoria kantiana (com o imperativo categórico) e o principialismo (a partir de quatro princípios), baseia-se em juízos ou princípios pré-concebidos, anteriores à experiência. Já a discussão ética baseada em fundação funda-se na experiência, a partir da que é vivido. Stengers (2002) é a referência que dá corpo a esta discussão e nos ajuda a sustentá-la, ainda que o foco da sua discussão seja, não a ética, mas a epistemologia. Stengers (2002) parte da distinção entre fundamento e fundação feita por Deleuze (1988). Vejamos o que ele nos diz:

[...] devemos distinguir a fundação e o fundamento. A fundação concentre ao solo e mostra como algo se estabelece sobre este solo, ocupa-o e o possui; mas o fundamento vem sobretudo do céu, vai do ápice às fundações, avalia o solo e o possuidor de acordo com um título de propriedade. O hábito é a fundação do tempo, o solo movente ocupado pelo presente que passa. Passar é precisamente a pretensão do presente. Mas o que faz com que o presente passe e que se apropria do presente e do hábito deve ser determinado como fundamento do tempo. O fundamento do tempo é a Memória. Foi visto que a memória, como síntese ativa derivada, repousa sobre o hábito: com efeito, tudo repousa sobre a fundação. Mas o que constitui a memória não é dado deste modo. No momento em que ela se funda sobre o hábito, a memória deve ser fundada por uma outra síntese passiva, distinta do hábito. E a síntese passiva do hábito remete a esta síntese passiva mais profunda que é da memória: Habitus e Mnemósina, ou a aliança do céu e da terra. O Hábito é a síntese originária do tempo que constitui a vida do presente que passa; a Memória é a síntese fundamental do tempo que constitui o ser do passado (o que faz passar o presente) (p. 85).

Nesta esteira argumentativa, pretendemos desviar dos enunciados éticos acerca da autonomia que venham antes do céu (o que é autonomia nos seus fundamentos), preferindo aqueles que são da ordem do possível (que autonomia pode ser experimentada e conceituada), aqueles que "se diferenciam a posteriori, consoante uma lógica que não é aquela do juízo, em busca de um fundamento, e sim a da fundação: 'Aqui, nós podemos'" (Stengers, 2002, p.100).

A ética como fundação se aproxima do que Spink (2008) chama de visão performática da ética - algo constitutivo da prática diária e sobre a qual somos discursivamente competentes -, enquanto a ética baseada em fundamentos percorreria o caminho inverso - o que a autora chama criticamente de uma lista de itens a serem verificados para fornecer uma garantia moral de bom comportamento. Para Passos e Barros (2000), a fundação é uma forma de implicação e de interferência que é ativa na produção tanto do seu objeto quanto do sujeito. Para os autores, devemos aceitar que este ato é sem fundamento. No entanto, ao abandonarmos as garantias do fundamento, o pensamento corre o risco de se perder na indiferença e no relativismo. É em reação a esta ameaça que devemos afirmar nossas escolhas conceituais e definir nossas posições críticas.

As discussões éticas de fundamento trazem um problema central para a saúde mental, pois supõem, anteriormente à experiência, aqueles que podem ou não agir de forma autônoma. Em tais suposições, indivíduos são separados em categorias pelos jogos de forças dominantes. Uma ética de fundação procura basear-se na experiência e tem como limite a interação com o outro.

Ao tecermos uma conceituação de autonomia imbricada com seu exercício, ou seja, uma autonomia que venha do solo e não do céu, uma conceituação que se faça da experiência e não da teorização prévia, entendemos a linguagem (o que se conceitua) como pragmática política (o que se exercita). Assim, temos uma noção de autonomia que é performática, que se faz na/da experiência, convocando reflexões éticas e políticas, também fundadas na experiência.

Tedesco (2012) explica que, para acontecer a performatividade, há necessidade de especificações não linguísticas: são as condições de efetuação do ato, que parecem ser definidas no 'exterior', nas circunstâncias em que se profere o dito. A enunciação "declaro o réu culpado", exemplifica Tedesco (2012), só tem peso jurídico se as circunstâncias empíricas Ihe conferirem sentido (proferida por um juiz de direito durante sessão reconhecidamente jurídica). Ou seja, o sentido das enunciações depende do mundo empírico, dos fatores circunstanciais, da dimensão extralinguística. Assim, toda enunciação é performativa, e é a força performativa da linguagem, e não sua competência representativa, que está em jogo. Deste modo, o extralinguístico, na medida em que decide o sentido, passa também a compor a linguagem.

É nesta lógica de uma autonomia que se faz fazendo que é impossível para nós propormos a discussão a respeito da autonomia do outro, do usuário. Pois, para falar dela, teríamos que buscá-la no alto. Aqui debaixo, com os pés na terra, todo questionamento sobre a autonomia implica em colocar a si próprio em questão. 
Chegamos, então, a uma noção de autonomia que se dá por fundação, não por princípios, dá-se por pragmática e tem por prerrogativa o efeito de autonomização. Embora na autonomização não se tenha princípios previamente definidos - uma vez que só se pode pensar nas possibilidades de autonomia em pragmática, sentindo onde o caminhar cria calos nos pés, conhecendo as condições de possibilidade e o modo como estas condições se articulam em cada encontro da existência -, há prerrogativas como a consideração ao desejo, a possibilidade de diálogo, de negociação, de invenção (Passos et al, 2013). A cogestão, por exemplo, pode ser entendida também como uma estratégia de autonomização e protagonização dos diferentes sujeitos (trabalhadores, gestores, usuários e familiares) implicados no processo de produção de saúde. Quando colocada em ação, ela cria condições para diferentes expressões da autonomia.

Após esta breve revisão conceitual do termo 'autonomia', encontramo-nos descontentes com a forma kantiana de conceituar autonomia, por entendermos que o conceito é performativo, não apriorístico e, portanto, deve se dar nas relações, no mundo da vida - nesse ponto, as críticas de Nietzsche (1882/1999) vêm colaborar com as possibilidades de uma autonomia que é criada e que inventa modos de ser. Também discordamos do entendimento dado pela Ética Principialista, baseada na capacidade racional do agente e tão presente nas práticas de saúde centradas em modelos biomédicos. Entendemos a autonomia como um exercício possível e complexo para qualquer ser humano, para o qual a capacidade de deliberação envolve uma gama de forças, não podendo ser medida unicamente pelas condições cognitivas do indivíduo. Estes embates nos levaram para uma autonomia pensada em redes e firmada pelas políticas públicas nacionais de saúde. Nossa tentativa não é apenas reafirmar o termo sempre presente nas políticas, pois, como dissemos, nelas ele é apenas citado, mas não problematizado. Nosso intuito foi ter alguma notícia do conceito em diferentes perspectivas filosóficas, apostando na abordagem de Kinoshita (2001) que, inspirada em Maturana e Varela (2004), propõe uma autonomia não como autossuficiência, mas como suficiente quando encontra pontos de apoio, quando tem uma rede com quem contar.

\section{Uma viagem sem porto de chegada}

A viagem à Montreal serviu de dispositivo para a pesquisa possibilitando a construção de um plano comum não-homogêneo, anti-universal. Isto é, a partir da dissolvência do ponto de vista do pesquisador, da habitação de um território não-lugar, criou-se um comum. Embora singulares, estávamos lado a lado, usuários de psicofármacos ou não, buscando autonomizações. Éramos um comum, não no sentido de 'ser como um', mas no sentido de 'ser como qualquer um'. É um comum que comporta uma heterogeneidade, um comunismo que não cabe nos limites do homogêneo, da identidade pessoal ou grupal. Por acompanhar este processo, afirmamos, não uma autonomia, mas um devir-autonômo.

Buscamos a experiência que colocasse obstáculos a nossa independência, que nos colocasse em apuros. Então, viajamos. Uma viagem sem retorno, nas asas de um coletivo que se contrai como rede de apoio. Não sendo autônomos, seria preciso construir processos autonomizantes. Propomos um laboratório in vita, que nos oferecia a possibilidade de colocarmos obstáculos à autonomia, forçando-a a resistir e a se fazer em performance. Tínhamos, como obstáculos, a inexperiência em viagens internacionais, o domínio somente de nossa língua de origem, convivermos entre dez pessoas em um apartamento de três quartos, estarmos longe dos familiares e conhecidos, termos restrições de acesso aos meios de comunicação (devido ao idioma), sermos em maioria usuários de psicofármacos e estarmos distanciados dos nossos médicos e outros profissionais de saúde de confiança.

Entendemos a contração de um coletivo que é autônomo na medida em que é cogestivo. Chegamos a uma autonomia pensada não como um estado de coisas, não como algo que se conquiste ou se possua. Não como propriedade, mas como performatividade, como emergente de certas práticas de autonomização. Autonomia não tem fundamento, só tem fundação; isso quer dizer que ela precisa ser constantemente refundada. Não tendo fundamento, ter autonomia obriga o confronto com experiências que são fora da autonomia, mas são processos de autonomização.

A viagem como laboratório nos permitiu assumirmos o destino de nossos dias contando com o apoio e a paciência das pessoas que encontrávamos. Ao nos lançarmos em terras desconhecidas, sem domínio da língua local e com modesta verba, estávamos todos lançados a experimentar uma autonomia possível e a colocar em segundo plano os diagnósticos psiquiátricos que nos foram atribuídos. 
Das provocações de uma autonomia em ato, que se assume como performatividade, fica a interrogação nascida deste caminhar: como assumir posturas éticas por fundação, que venham a partir da experiência e não antes delas, sem cairmos em relativismos ou descompromisso com o outro? Entre as dúvidas e as angústias que permanecem nos assombrando, a esta altura, diante do nosso desconhecimento sobre si, sobre autonomia, sobre independência, fica a gana e a esperança na possibilidade de que, das rupturas do não-saber, emerja a invenção de modos de vida e a criação de outros devires.

\section{Referências}

Alvarez, J., \& Passos, E. (2009). Cartografar é habitar um território existencial. In E. Passos, V. Kastrup, \& L. Escóssia (Orgs.), Pistas do método da cartografia: pesquisa- intervenção e produção de subjetividade (pp. 131-149). Porto Alegre: Sulina.

Aristóteles (2011). A política. (N. S. Chaves, Trad.). Rio de Janeiro: Saraiva.

Barros, L. P., \& Kastrup, V. (2009). Cartografar é acompanhar processos. In E. Passos, V. Kastrup, \& L. Escóssia (Orgs.), Pistas do método da cartografia: pesquisa- intervenção e produção de subjetividade (pp. 52-75). Porto Alegre: Sulina.

Beauchamp, T. L. (2007). The 'Four Principles' Approach. In R. Gillon (Org.), Principles of health care ethics (pp. 3-12). Chichester: John Wiley \& Sons.

Beauchamp, T. L.; \& Childress, J. F. (2002). Princípios de ética biomédica (4⿳a ed.). São Paulo: Edições Loyola.

Deleuze, G. (1974). Lógica do sentido. São Paulo: Perspectiva.

Deleuze, G. (1988). Diferença e repetição. Rio de Janeiro: Graal.

Deleuze, G., \& Guattari, F. (1997) Acerca do ritornelo. In G. Deleuze \& F. Guattari. Mil Platôs: capitalismo e esquizofrenia (Vol. 4, pp. 100149). São Paulo: Editora 34.

Eirado, A., \& Passos, E. (2004). A noção de autonomia e a dimensão do virtual. Psicologia Em Estudo, 9(1), 77-85. doi: 10.1590/ S1413-73722004000100010

Foucault, M. (2000). As palavras e as coisas. São Paulo: Martins Fontes.

Foucault, M. (2006). A hermenêutica do sujeito. São Paulo: Martins Fontes.

Galeano, E. (2007). De pernas pro ar: a escola do mundo ao avesso (9a ed.). Porto Alegre: L\&PM.

Gama, B. C. (2010). Políticas do si mesmo - por uma autonomia enquanto função em tempos de biopoder (Dissertação de Mestrado). Recuperado de https://bdtd.ufs.br/handle/tede/2410

Kant, I. (2011). Fundamentação da metafísica dos costumes. Coimbra: Edições 70. (Obra original publicada em 1785)
Kastrup, V., \& Passos, E. (2013). Cartografar é traçar um plano comum. Fractal: Revista De Psicologia, 25(2), 263-280. Recuperado de http://www.uff.br/periodicoshumanas/index.php/Fractal/article/ view/1109/870

Kinoshita, R. T. (2001). O outro da reforma: contribuições da teoria da autopoiese para a problemática da cronicidade no contexto das reformas psiquiátricas (Tese de Doutorado). Recuperado de http:// libdigi.unicamp.br/document/?code=vtls000218828

Maturana, H. R., \& Varela, F. (2004). A árvore do conhecimento: as bases biológicas do entendimento humano. São Paulo: Palas Athena.

Moraes, M. \& Kastrup, V. (2010). Exercícios de ver e não ver: arte e pesquisa COM pessoas com deficiência visual. Rio de Janeiro: Nau.

Nietzsche, F. (1999). A gaia ciência. In F. Nietzsche (Org.), Obras incompletas. Coleção Os Pensadores. São Paulo: Nova Cultural. (Obra original publicada em 1882)

Passos, E., \& Barros, R. B. (2000). A construção do plano da clínica e o conceito de transdisciplinaridade. Psicologia: Teoria e Pesquisa, 16(1), 71-79. doi:10.1590/S0102-37722000000100010

Passos, E., \& Barros, R. B. (2009). A cartografia como método de pesquisa intervenção. In E. Passos; V. Kastrup; \& L. Escóssia (Orgs.), Pistas do método da cartografia: pesquisa-intervenção e produção de subjetividade (pp. 17-31). Porto Alegre: Sulina.

Passos, E., \& Eirado, A. (2009). Cartografia como dissolução do ponto de vista do observador. In E. Passos; V. Kastrup; \& L. Escóssia (Orgs.), Pistas do método da cartografia: pesquisa- intervenção e produção de subjetividade (pp. 109-130). Porto Alegre: Sulina.

Passos, E.; Palombini, A. L.; Campos, R. O.; Rodrigues, S. E.; Melo, J.; Maggi, P. M; ... Emerich, E. (2013). Autonomia e cogestão na prática em saúde mental: o dispositivo da gestão autônoma da medicação (GAM). Aletheia, 41(1), 24-38. Recuperado de http://pepsic.bvsalud.org/scielo.php?script=sci_arttext\&pi$d=S 1413-03942013000200003 \&$ Ing=pt\&tIng=pt

Poli, M. C. (2006). O sujeito na ciência: questões à bioética. Psicologia Social, 18(3). doi: 10.1590/S0102-71822006000300002

Santarosa, M., \& Dimov, T. (2014, 19 de setembro). A viagem continua... (arquivo de vídeo). Recuperado de https://www.youtube.com/ watch?v=30k4Ee52PLk

Spink, P. K. (2008). O pesquisador conversador no cotidiano. Psicologia \& Sociedade, 20(1), 70-77. doi: 10.1590/ S0102-71822008000400010

Stengers, I. (2002). A invenção das ciências modernas. São Paulo: Editora 34.

Tedesco, S. H. (2012). Pensando a ética da clínica das drogas: linguagem, subjetivação e a experiência das drogas (Tese de Concurso para Professor Titular da Universidade Federal Fluminense, Rio de Janeiro). Recuperado de https://pt.scribd.com/document/220175172/ Tese-de-Coconcurso-UFF-2012-Silvia-Tedesco.

Zourabichvili, F. (2004). O vocabulário de Deleuze. Rio de Janeiro: Relume Dumar.

${ }^{1}$ Conforme consta no site oficial do Fora do Eixo, a Semana do Audiovisual (SEDA), é um dos projetos que compõe a grade de ações do Fora do Eixo, que, por sua vez, é uma rede sociocultural presente em mais de 200 cidades brasileiras, desenvolvendo ações culturais pautadas nos princípios da Economia Solidária, atuando no campo da cultura independente e livre. A SEDA contempla diversas cidades, em todas as regiões no Brasil e América Latina. Tem como principais metas o fomento da produção artística deste setor, a circulação de profissionais, obras e tecnologias, bem como a formação de novos agentes culturais, buscando a articulação entre os setores do audiovisual. 
Autonomias errantes: Processos de autonomização em saúde mental

Marciana Zambillo, Mestre em Psicologia Social e Institucional pela

Universidade Federal do Rio Grande do Sul (UFRGS), Doutoranda em Psicologia Social e Institucional pela Universidade Federal do Rio

Grande do Sul (UFRGS).

Endereço para correspondência: Rua Comendador Rodolfo Gomes,

n. 403, ap. 303, Menino Deus. Porto Alegre (RS). CEP: 90.150-101.

Telefone: (51) 98257-6346.

E-mail: marcianazambillo@gmail.com

Analice de Lima Palombini, Doutorado em Saúde Coletiva pela Universidade Estadual do Rio de Janeiro (UERJ), Docente do Instituto de Psicologia da Universidade Federal do Rio Grande do Sul (UFRGS) no curso de graduação em Psicologia e no Pós-Graduação em Psicologia Social e Institucional (PPGPSI), do qual em 2014 assumiu a coordenação. Participa também da coordenação da Residência Integrada em Saúde Mental Coletiva da mesma Universidade.

E-mail: analice.palombini@ufrgs.br

Recebido em 05.Jan.16

Revisado em 15.Jan.17 Aceito em 07.Fev.17 